\title{
Nonlinear sea level trends from European tide gauge records
}

\author{
S. M. Barbosa, M. J. Fernandes, and M. E. Silva \\ Faculdade de Ciencias, Universidade do Porto, Rua do Campo Alegre, 687, 4169-007 Porto, Portugal \\ Received: 14 May 2003 - Revised: 10 October 2003 - Accepted: 3 February 2004 - Published: 8 April 2004
}

\begin{abstract}
Mean sea level is a variable of considerable interest in meteorological and oceanographic studies, particularly long-term sea level variation and its relation to climate changes. This study concerns the analysis of monthly mean sea level data from tide gauge stations in the Northeast Atlantic with long and continuous records. Much research effort on mean sea level studies has been focused on identifying long-term linear trends, usually estimated through leastsquares fitting of a deterministic function. Here, we estimate nonparametric and robust trends using lowess, a robust smoothing procedure based on locally weighted regression. This approach is more flexible than a linear trend to describe the deterministic part of the variation in tide gauge records, which has a complex structure. A common trend pattern of reduced sea levels around 1975 is found in all the analysed records and interpreted as the result of hydrological and atmospheric forcing associated with drought conditions at the tide gauge sites. This feature is overlooked by a linear regression model. Moreover, nonlinear deterministic behaviour in the time series, such as the one identified, introduces a bias in linear trends determined from short and noisy records.
\end{abstract}

Key words. Oceanography: physical (sea level variations); Hydrology (water balance)

\section{Introduction}

Sea level is a variable of considerable interest in meteorological and oceanographic studies. Concerns of a global warming due to the injection of $\mathrm{CO}_{2}$ into the atmosphere and consequent greenhouse effect put a pressing demand on the scientific community for precise measurements and forecasts of sea level change.

Sea level is currently measured by two methods: tide gauges and satellite altimetry. Satellite altimetry allows global measurements of absolute sea level in a precise reference frame. However, this is a considerably recent technique and altimetric records span a time interval (less than two decades) which is too short to allow the detection of long-term trends

Correspondence to: S. M. Barbosa

(susana.barbosa@fc.up.pt) in sea level. Tide gauge measurements of sea level are available from the XIX century. These long records are the focus of much research effort on mean sea level, as they constitute the only source of historical, precise sea level measurements. The length of the available time series encourages the use of tide gauge data to study sea level change and its connection to climate variations.

Long-term sea level changes are caused by long-period tides (nodal, polar), meteorological effects (pressure, winds), climatic effects and teleconnection patterns (NAO, ENSO, etc.), ocean circulation (geostrophic currents and thermohaline circulation) and steric effects (changes in sea water density due to variations of temperature or salinity). To understand sea level change the contribution of each of these effects to sea level variations must be assessed.

In this study we analyse monthly mean sea level data from tide gauge stations in the Northeast Atlantic with long and continuous records: Newlyn, Brest and Cascais. Previous work using tide gauge records from these stations was carried out by Woodworth et al. (1991), who estimated a linear trend of approximately $1-2 \mathrm{~mm} /$ year for sea level around the British Isles; Dias and Taborda (1988) studied Cascais data and estimated a linear trend of $1.3 \mathrm{~mm} /$ year; Araujo et al. $(2001,2002)$ estimated separate trends for tides, surges and mean sea level from Newlyn and Brest records.

These studies, as in most work on sea level change from tide gauge records, concentrate on the identification of linear trends, estimated through the least-squares fitting of a deterministic function. However, most tide gauge records exhibit different linear behaviour within different time periods, which makes estimation of long-term changes difficult. Therefore, the trend component needs to be flexible enough so that deterministic variations in the series are correctly modelled, particularly for short records.

Here we adopt the concept, widely used in the statistics literature, of trend as a long-term variation rather than in the strict sense of a linear model. The deterministic variation of sea level as measured by tide gauge records is estimated using lowess (Cleveland, 1981), a smoothing procedure which combines the simplicity of linear least squares regression with the adaptability of nonlinear regression methods giving flexible and robust nonparametric trends. 
Table 1. Analysed data.

\begin{tabular}{lccc}
\hline Station & Latitude & Longitude & Period \\
\hline Newlyn & $50.1^{\circ} \mathrm{N}$ & $5.5^{\circ} \mathrm{W}$ & $1948-2001$ \\
\hline Brest & $48.4^{\circ} \mathrm{N}$ & $4.5^{\circ} \mathrm{W}$ & $1953-2000$ \\
\hline Cascais & $38.7^{\circ} \mathrm{N}$ & $9.4^{\circ} \mathrm{W}$ & $1961-1989$ \\
\hline
\end{tabular}

Table 2. Regression models - IB response.

\begin{tabular}{lccc}
\hline Station & IB coefficient $(\mathrm{mm} / \mathrm{mb})$ & Standard error & $R^{2}$ \\
\hline Newlyn & -11.1 & 0.34 & 62.9 \\
\hline Brest & -13.4 & 0.42 & 65.3 \\
\hline Cascais & -13.7 & 0.54 & 65.3 \\
\hline
\end{tabular}

2 Data

Mean Sea Level (MSL) data were obtained from the Permanent Service for Mean Sea Level (PSMSL) for the tide gauge stations in the Northeast Atlantic with longest records: Newlyn, Brest and Cascais (Fig. 1). Sea levels are adjusted to a Revised Local Reference (RLR) datum defined relative to the tide gauge benchmark. Monthly data were used to filter short-period fluctuations and tides. To ensure data consistency and continuity, subsets of the available data were selected (Table 1).

Monthly climate data were extracted from the NCEP reanalysis data set on a $2.5 \times 2.5$ grid, provided by the NOAA-CIRES Climate Diagnostics Center, Boulder, Colorado, USA, from their Web site at http://www.cdc.noaa.gov. The grid point nearest to each tide gauge station was chosen as representative. Reanalysis time series of sea level pressure (SLP), precipitation rate, zonal wind and meridional wind were extracted.

Sea surface temperature (SST) monthly data were obtained from the COADS data set provided by the NOAACIRES Climate Diagnostics Center.

Data analysis was carried out using R software for statistical computing (Ihaca and Gentleman, 1996), and maps with Generic Mapping Tools (Wessel and Smith, 1998).

\section{Data analysis}

A standard approach for analysis of mean sea level tide gauge data is to fit by least squares a mathematical function with components such as mean (the mean over some suitable period), trend (linear trend) and a periodic term. This separation is useful but does not take into account that the mean and trend components may also include averaged effects of meteorological origin.

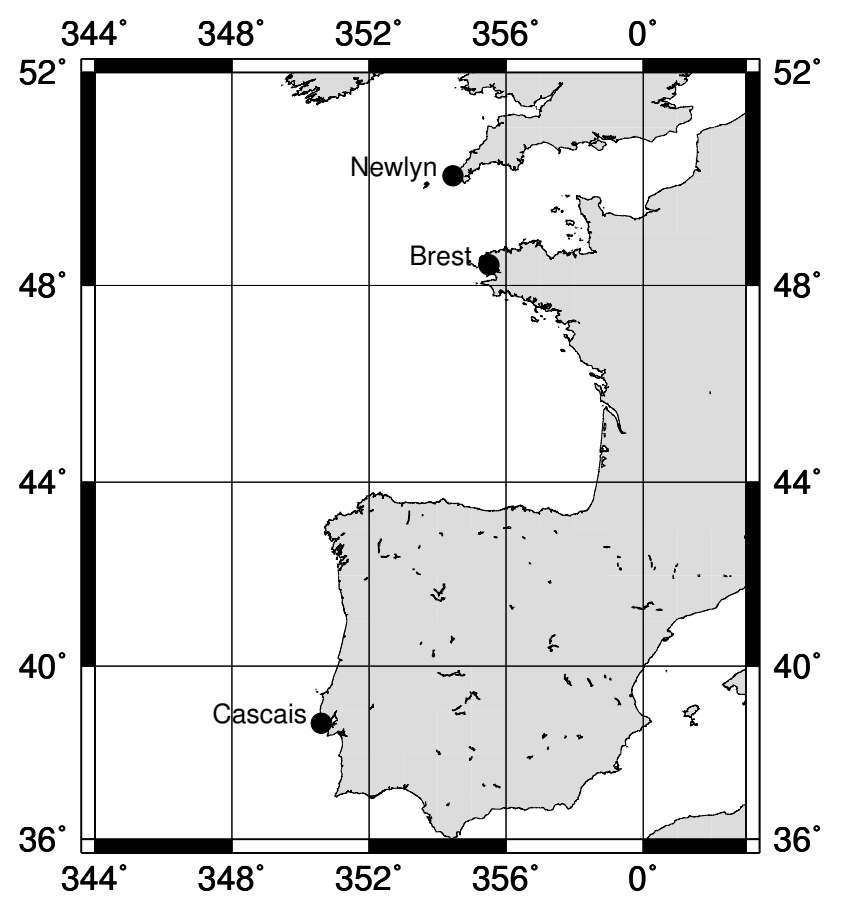

Fig. 1. Study area with tide gauge locations.

In this study MSL time series are first seasonally-adjusted (corrected of seasonal effects) and corrected of pressure effects; then a flexible nonparametric smoothing method is applied to estimate trend.

Spectral analysis was used to identify cyclical variations in the tide gauge records. Seasonal and other periodic variations were investigated by computing the cumulative periodograms for each MSL time series (Fig. 2). All plots show clear jumps at frequency 1 corresponding to the annual cycle. Other low frequency cycles are within the statistical confidence limits. Seasonal indices (monthly mean values) were calculated and subtracted to the original time series to remove the annual cycle.

Pressure influences sea level through the Inverted Barometer (IB) response. The scatterplots of the seasonally-adjusted MSL versus SLP time series show, as expected, a linear relationship (Fig. 3). To reduce background noise and data variability, a linear regression of MSL on SLP was carried out. The fitted regression lines give IB coefficients near the theoretical value of a $10 \mathrm{~mm}$ sea level rise for a $1 \mathrm{mb}$ drop in atmospheric pressure, and explain more than $60 \%$ of the MSL variance for all series (Table 2). Differences between the estimated IB response and the theoretical value are probably due to winds, which are correlated with pressure (Pugh, 1996).

\subsection{Estimation of trends}

Smoothing methods, such as moving averages, kernel smoothing, or splines are flexible ways to estimate long-term trends (Shumway and Stoffer, 2000). 

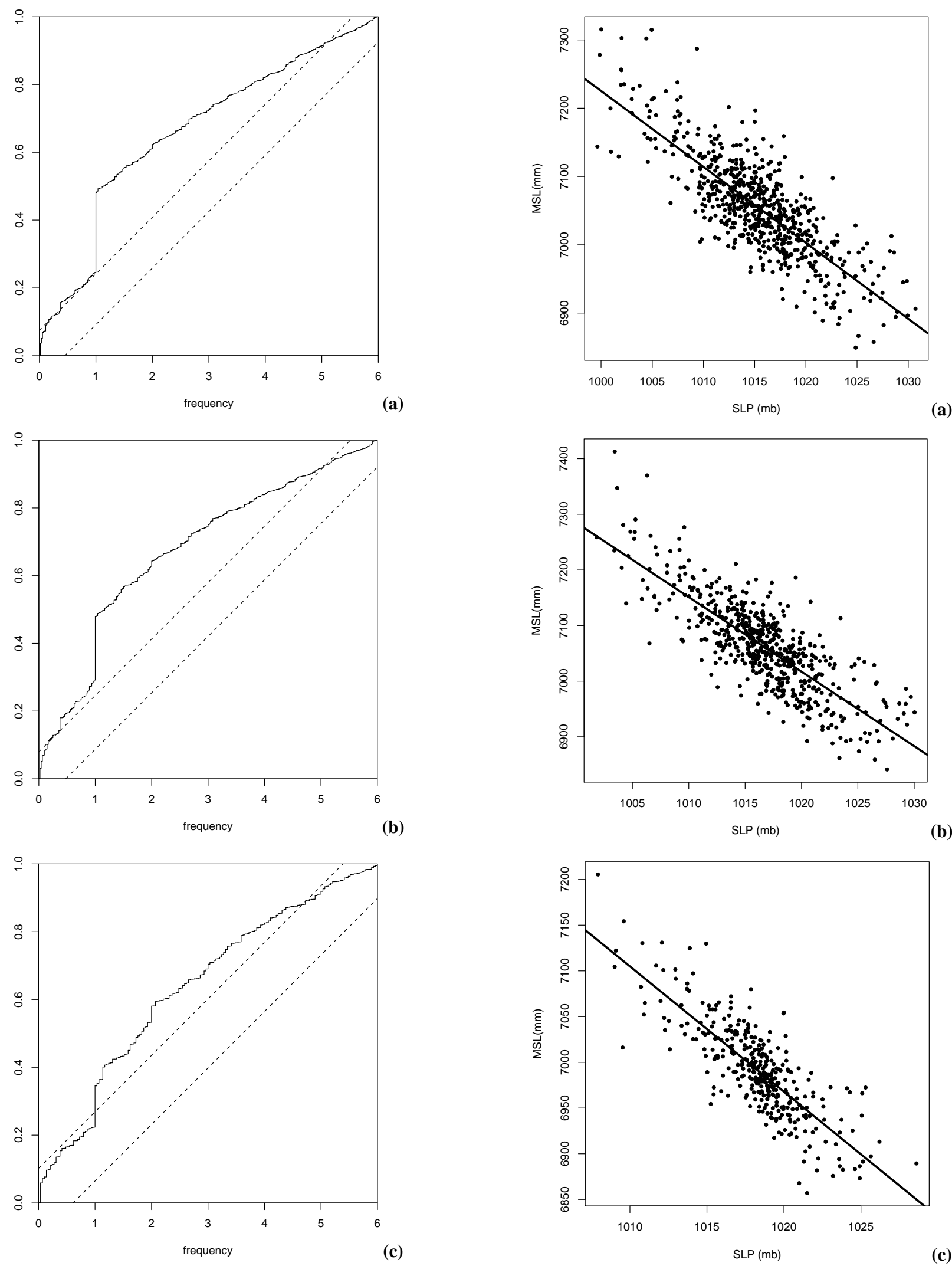

Fig. 2. Cumulative periodograms for MSL time series. (a) Newlyn, (b) Brest and (c) Cascais.

Fig. 3. Regression models: MSL versus SLP (a) Newlyn, (b) Brest and (c) Cascais. 
Lowess, an acronym for "locally weighted scatterplot smoothing", based on locally weighted regression, is a powerful exploratory tool to enhance and display the underlying structure in the data. It is a nonparametric method, focusing on the estimation of a curve rather than on the estimation of coefficients as in parametric regression, able to provide more insight into data structure in the presence of nonlinear behaviour than a more rigid description. Lowess was used to estimate sea level trends from each tide gauge record.

Lowess is a local procedure: each estimated value is determined by a subset of neighbouring data points in a predefined window. The choice of the window span is a trade-off between bias and variance, in a compromise between resolution and significance. Larger values give smoother estimates. The same window-span of 10 years was used for the three tide gauge records and chosen to bring out what might be considered obvious features in the data set.

For each observation $x_{0}$, regression weights given by the tricube function $W$ are computed for each neighbour-point $x_{i}$ in a window of width $2 h$ centred at $x_{0}$ :

$W(z)=\left\{\begin{array}{cc}\left(1-|z|^{3}\right)^{3} & |z|<1 \\ 0 & |z| \geq 1\end{array} \quad z=\left(x_{i}-x_{0}\right) / h\right.$.

These weights are used to compute the fitted value at $x_{0}$, $\widehat{y}_{i}=a+b\left(x_{i}-x_{0}\right)$; coefficients $a, b$ are determined by minimising the weighted residual sum of squares.

If data contain outliers, the smoothed values can become distorted; robustifying iterations are carried out to reduce the influence of atypical cases on the estimated curve. The residuals from each fitted value are computed, $E_{i}=y_{i}-\widehat{y}_{i}$ and the median absolute deviation from the median residual ( $M A D)$ used as a robust measure of the spread of the residuals:

$$
M A D=\operatorname{median}\left|E_{i}-\operatorname{median}\left(E_{i}\right)\right| .
$$

Resistance weights $v_{i}$ are computed using a bisquare weight function $W_{B}$ :

$$
W_{B}(z)=\left\{\begin{array}{cr}
\left(1-z^{2}\right)^{2} & |z|<1 \\
0 & |z| \geq 1
\end{array} \quad z=E_{i} / 6 M A D .\right.
$$

A new, local weighted regression is then computed using both local weights and the resistance weights. This process continues through further iterations, repeatedly smoothing the data and at each iteration down-weighting the points for which errors are larger. The net result is a fitted line that is insensitive to outliers.

Lowess trends estimated from the tide gauge records (Fig. 4) reflect consistent changes in the sea level time series. The fitted curves show some interannual variability (with periods of approximately 3 years), superimposed on a moderately increasing trend. Comparing the trend estimates, a marked reduction in sea level around 1975 is observed at the three locations. This is not only the most pronounced troughout, but also the only feature that is common to the three tide gauge records. Due to the intrinsic nature of tide gauge measurements, prone to many different error sources, the geographical coherence is important to distinguish local phenomena (instrumental errors, subsidence, PGR) from true physical phenomena affecting sea level at the tide gauge sites.

\subsection{Discussion}

The use of a robust, nonparametric method to estimate trends allowed one to detect distinct features of interannual variability in the analysed tide gauge records. The pronounced minimum identified in the trend pattern of all the sea level time series coincides with extreme climatic conditions in Europe, the 1975-76 drought, which was found to be a highly coherent event, both spatially and temporally, spreading from west to east across Northern Europe (Rodriguez and Monreal, 2000; Zaidman et al., 2002).

The primary driving factor for drought is rainfall deficiency. To investigate the drought conditions at the tide gauge areas, reanalysis precipitation data were used to calculate the percentage of precipitation deficiency relative to a 30-year average value (1960-1990), for winter and summer (Fig. 5).

The analysed precipitation data show that all the three tide gauge locations experienced severe precipitation deficits during the 1975-1976 period. Cascais experienced the most severe precipitation deficiency in the 1975 summer (less than $50 \%$ of normal precipitation), which was followed by a dry winter. The 1976 summer was wet but very hot and thus groundwater recovery occurred only in the 1977 winter due to the high evapotranspiration rate. In Brest and Newlyn the worst drought conditions occurred in the summer of 1976.

The 1975-1976 drought culminated in a succession of dry winters. Winter rainfall is critical for maintaining soil moisture storage and groundwater recharge as evaporation losses are low. The severity of the drought resulted from the hydrological impact of an exceptionally dry winter between two hot and dry summers $(1975,1976)$, leading to surface water and groundwater deficits.

Sea surface salinity is correlated with evaporation minus precipitation. In most areas of the North Atlantic precipitation is low and evaporation exceeds precipitation (Juliano, 2003). The Atlantic Ocean has many areas of river discharge (compared to other oceans), which influence the salinity balance. This is particularly important at coastal locations. Salinity fluctuations influence sea level through density variations: an increase in salinity causes a reduction in sea level. A reduction in the freshwater input from rivers and an increase in sea water evaporation associated with the drought conditions increase salinity at coastal sites, affecting (at least to some extent) sea level measured by tide gauges. This effect of salinity increase should be particularly important at Cascais, due to its location near the Tagus estuarine zone. A sharp salinity change is unlikely because rainfall deficit has a lagged and smoothed impact on groundwater recharge and river flows. A quantitative study of salinity data during the drought period would be very interesting, but is hampered by the sparse available data. Measurements are made 

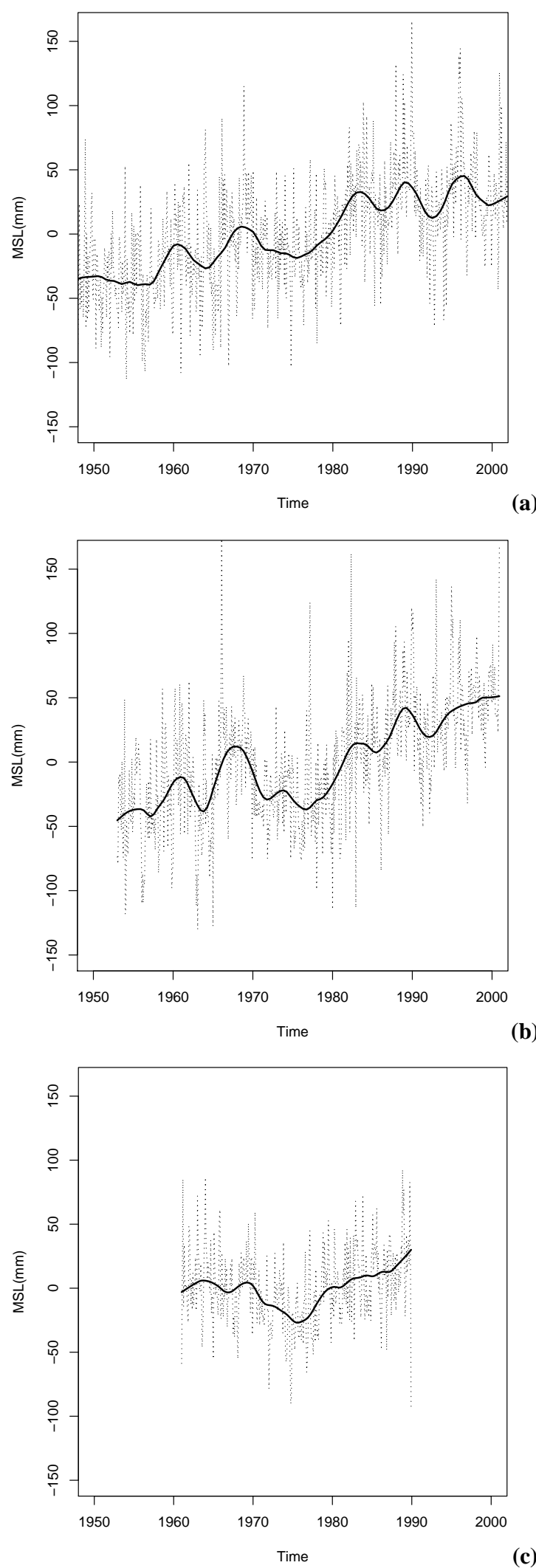

Fig. 4. Seasonally-adjusted and IB-corrected MSL time series (dashed line) and lowess trend (solid line). (a) Newlyn, (b) Brest and (c) Cascais.
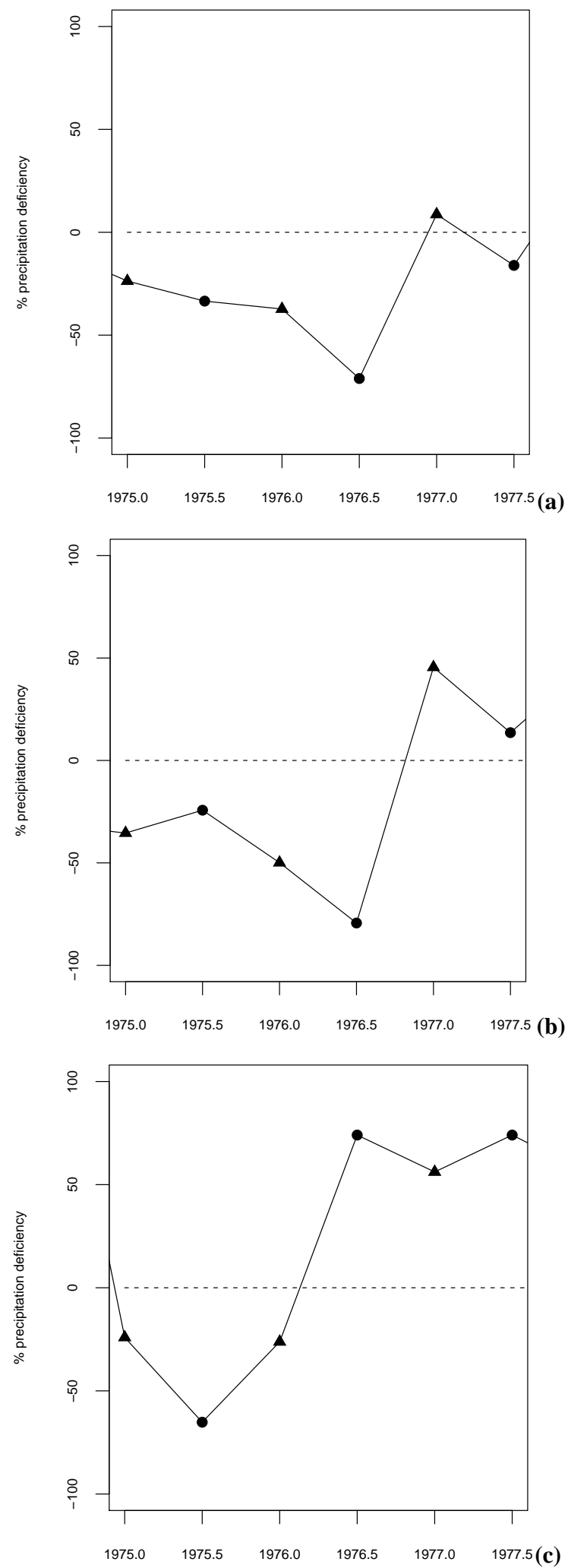

Fig. 5. Precipitation deficiency (\%) at tide gauge locations for winter (triangles) and summer (circles), (a) Newlyn, (b) Brest and (c) Cascais. 


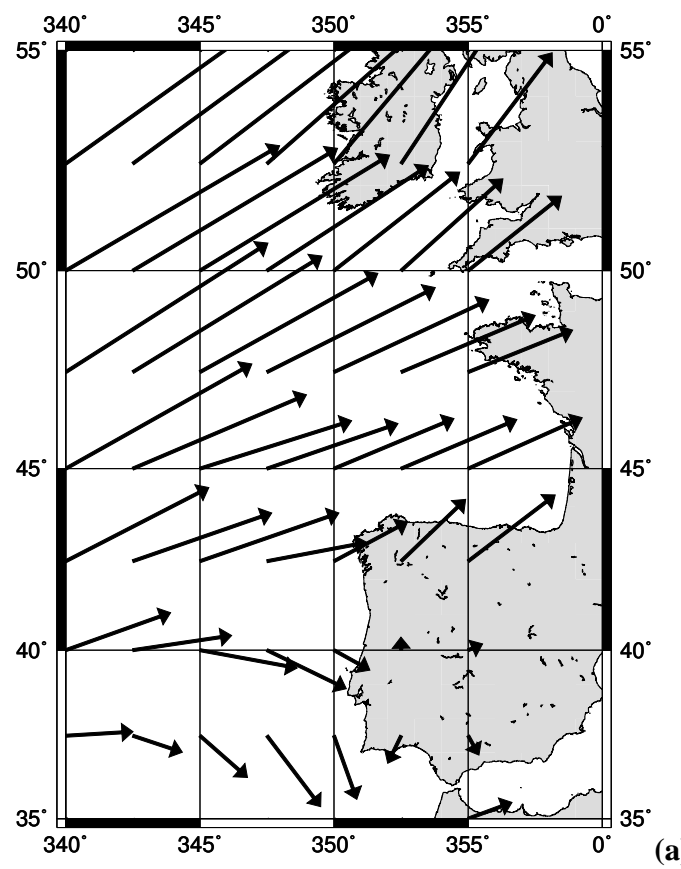

(a)

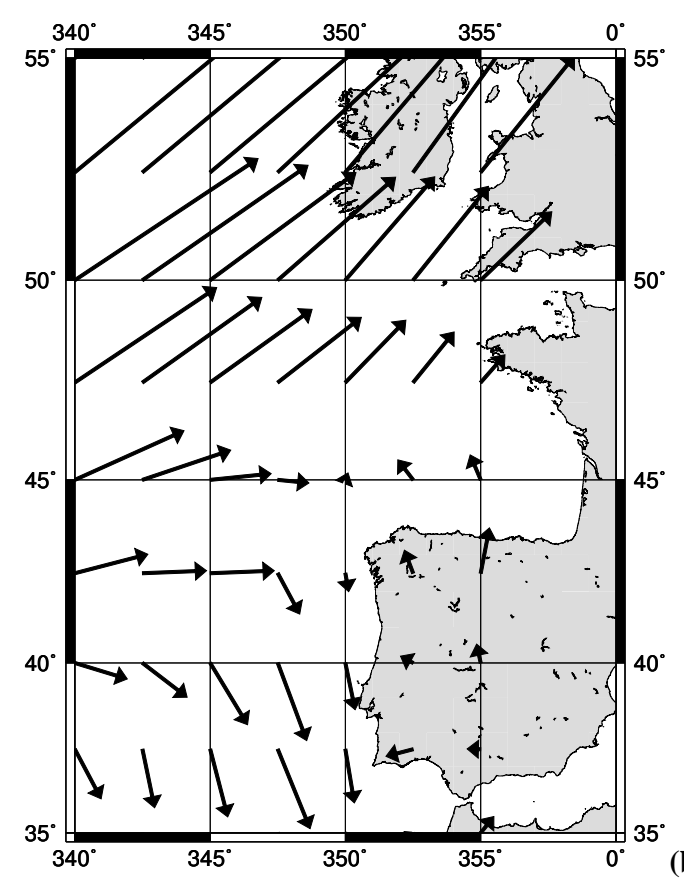

(b)

Fig. 6. Dominant winds - Winter. (a) Long-term average 19482001, (b) 1975-1976.

mainly by research vessels and ships of opportunity, since salinity data from remote sensing are not yet available (although salinity missions such as SMOS and AQUARIUS are being planned). Although drought is mainly characterised by unusually low rainfall, it is related to important atmospheric anomalies, such as winds, which also affect sea level. Seasonal time series of wind direction (azimuth) and magnitude (speed) were computed from the surface zonal (u) and

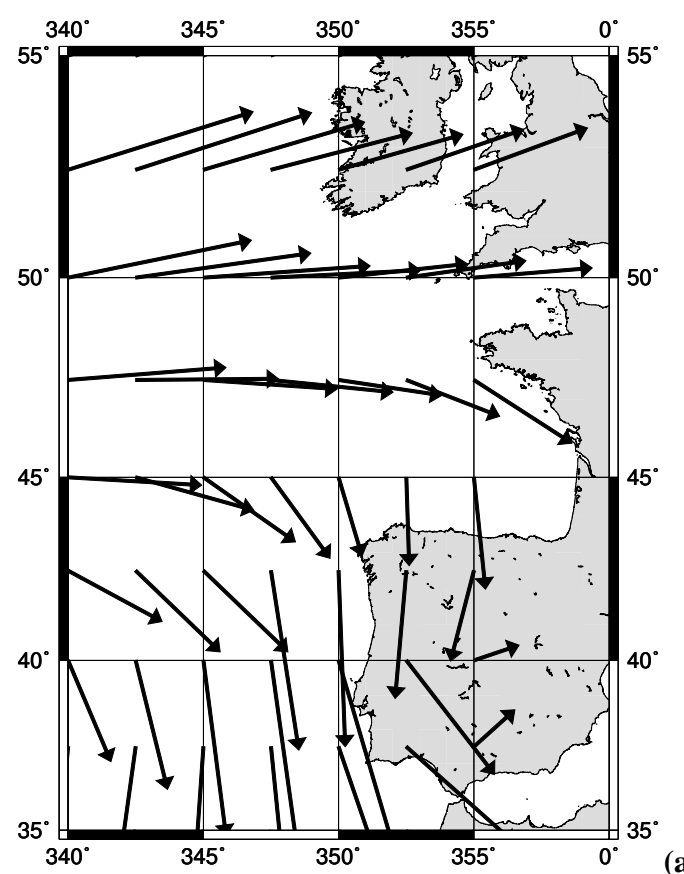

(a)

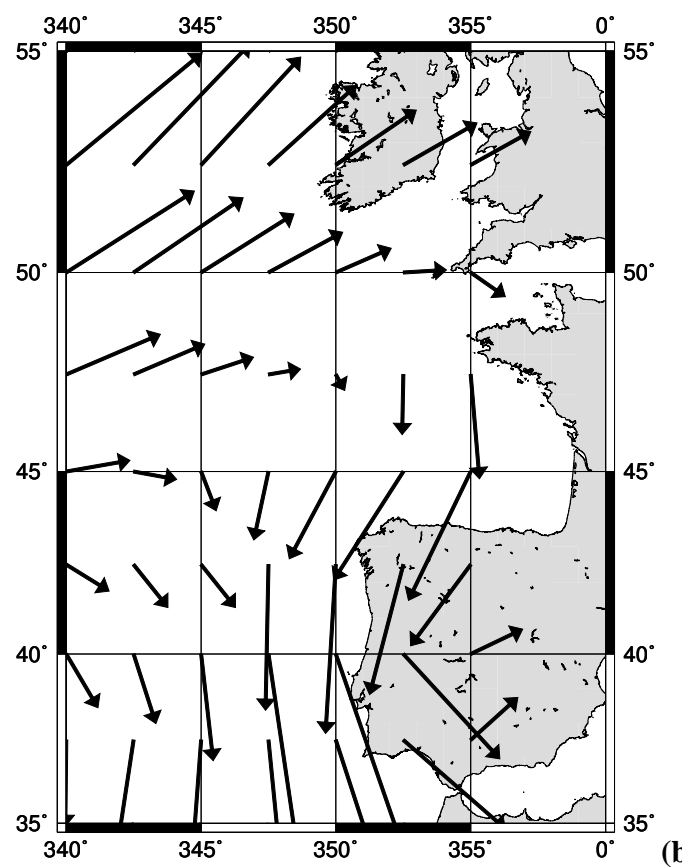

(b)

Fig. 7. Dominant winds - Summer. (a) Long-term average 19482001, (b) 1975-1976.

meridional (v) wind components. The spatial distribution of dominant winds during the 1975-1976 period was compared with a long-term (1948-2001) average for winter and summer (Fig. 6, Fig. 7). At the three tide gauge sites winds were unusually weak during the drought period. At Newlyn and Brest the dominant wind direction shifted from westerly to more northerly winds during summer, while at Cascais wind directions remained mainly unaltered. Monthly SST 


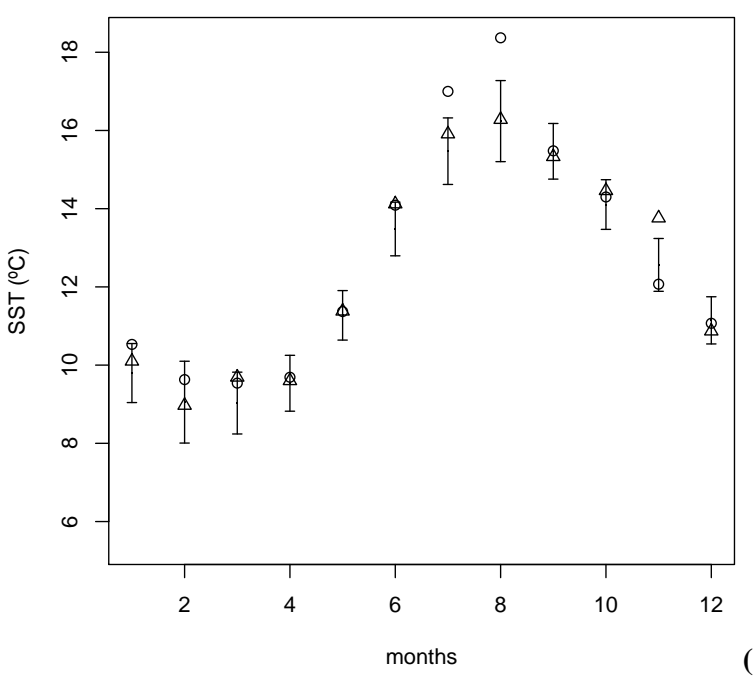

(a)

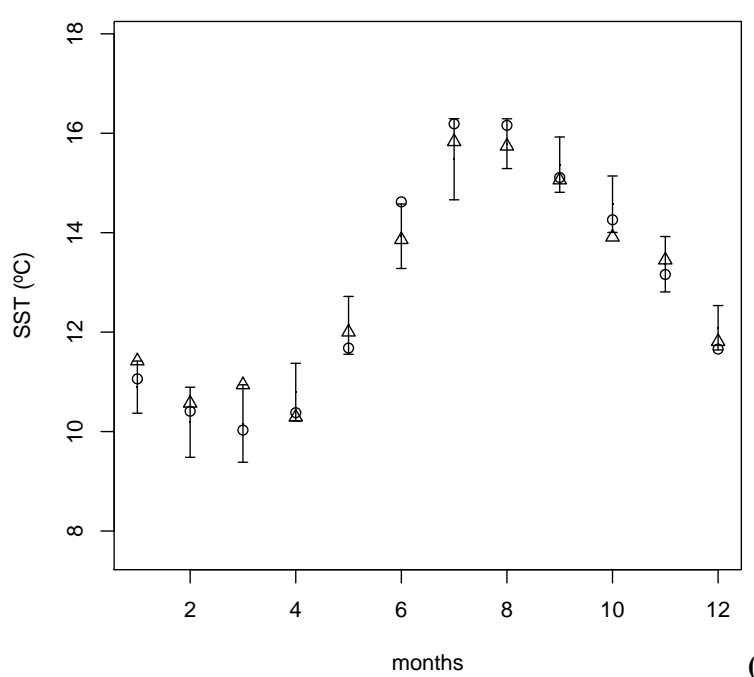

(b)

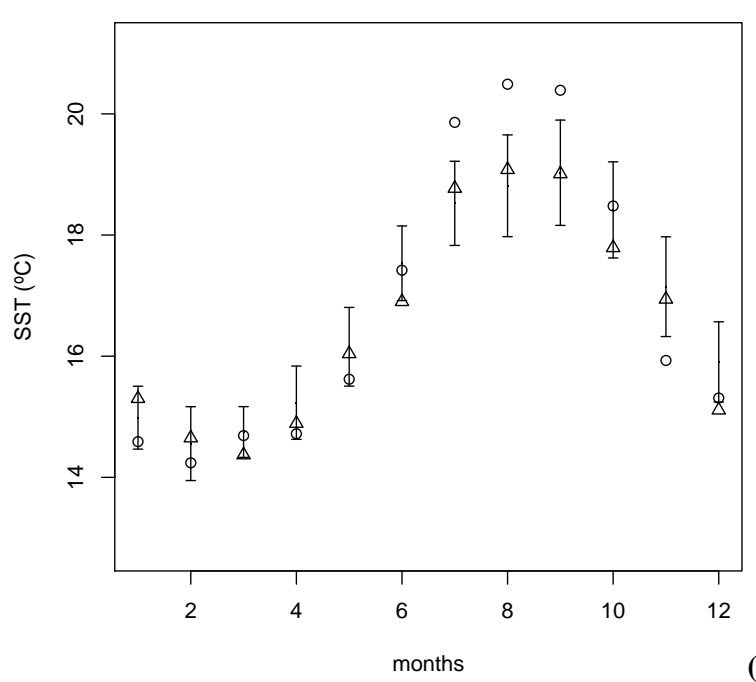

(c) values were analysed at each tide gauge location. For each month the long-term mean (1960-1997) and standard deviation were computed, and SST values from 1975-1976 were plotted on an error bar chart (Fig. 8). There are no significant changes in SST values for 1975 and 1976, except during the 1976 summer at Newlyn and Cascais, when sea temperature exceeded the average value by more than 1 standard deviation.

\section{Conclusions}

Nonparametric and robust lowess trends were estimated from tide gauge records in the Northeast Atlantic. This approach is more flexible than a linear trend to describe the deterministic part of the variation exhibited by MSL and therefore more suitable to model tide gauge series which have a complex deterministic structure. The trend patterns obtained are in good agreement with previous analysis of these data, in the sense of a slight increasing linear trend, but significant deviations from a linear behaviour are detected. In particular, a minimum corresponding to unusually low sea levels around 1975 was found in all the analysed tide gauge records, coincident with a strong drought event registered in Europe.

Drought conditions (rainfall deficiency and consequent increased evaporation and reduction in freshwater runoff) are expected to change the physical properties of sea water at coastal sites where tide gauges are located. The drought event itself is related to important atmospheric anomalies, which also affect sea level. Therefore, a direct cause-effect relation between sea level and drought is difficult to establish due to nonlinear and lagged interactions between the hydrological and climatic subsystems.

Another likely contribution to the low sea levels observed during the drought period was the unusually weak winds and shift in wind direction towards more offshore winds, particularly at northern stations.

The detection of significant slight temporal changes in a time series against a noisy background is a difficult task. The methodology adopted in this study, through a flexible description of sea level long-term variation, allowed one to extract physically meaningful information from the data, in this case the signature of a climatic event on sea level, which would be overlooked by a linear regression model. Moreover, nonlinearity in the deterministic variation of the time series, such as the one identified, introduces a bias in linear trends determined from short records.

Acknowledgements. Part of this work has been supported by program POCTI through the Centro de Investigação em Ciências Geoespaciais (CICGE)

Topical Editor N. Pinardi thanks D. Rosen and another referee for their help in evaluating this paper.

Fig. 8. Error bar plots of sea surface temperature at tide gauge locations for 1975 (triangles) and 1976 (circles). (a) Newlyn, (b) Brest and (c) Cascais. 


\section{References}

Araujo, I., Pugh, D., and Collins, M.: An intensive analysis of trends in sea level variability at Newlyn, in: Final workshop of COST Action 40, Hydrographic Institute of the Republic of Croatia, 93-96, 2001.

Araujo, I., Pugh, D., and Collins, M.: Trends in components of sea level around the English channel, in: TProceedings of 6th International Symposium LITORAL 2002, Eurocoast, Porto, Portugal, 107-114, 2002.

Cleveland, W. S.: Lowess: a program for smoothing scatterplots by robust locally weighted regression, Am. Stat., 35, 54, 1981.

Dias, J. M. A. and Taborda, R.: Evolucao recente do nivel medio do mar em Portugal, Anais do Instituto Hidrografico, 83-97, 1988.

Ihaca, R. and Gentleman, R.: R: a language for data analysis and graphics, J. Comput. Graph. Stat., 5, 299-314, 1996.

Juliano, M.: Determinacao e analise do sistema de circulacao oceanica tridimensional e clima do Oceano Atlantico, $\mathrm{PhD}$ thesis, University of Azores, 2003.
Pugh, D.: Tides, surges and mean sea level, John Wiley and Sons, 1996.

Rodriguez, J. and Monreal, T.: Regionalisation and drought characterisation in Europe, Centro de Estudios Hidrograficos del CEDEX, ARIDE Technical Report , \#9, 2000.

Shumway, R. H. and Stoffer, D. S.: Time series analysis and its applications, Springer, 2000.

Wessel, P. and Smith, W. H. F.: New improved version of the Generic Mapping Tools released, EOS Trans., AGU, 79, 579, 1998.

Woodworth, P., Shaw, S. M., and Blackman, D. L.: Secular trends in mean tidal range around the British Isles and along the adjacent European coastline, Geophys. J. Int., 593-609, 1991.

Zaidman, M. D., Rees, H. G. and Young, A. R.: Spatio-temporal development of dreamflow droughts in North-West Europe, Hydrol. Earth Syst. Sc., 733-752, 2002. 